\title{
O DIÁRIO NA REDE: PROPOSTA DE SEQUÊNCIA DIDÁTICA PARA O GÊNERO DIGITAL BLOG
}

\author{
Débora Cristina Longo Andrade*
}

\begin{abstract}
RESUMO: O objetivo deste trabalho é o de propor uma sequência didática que complemente o conteúdo de um material didático voltado a alunos do Ensino Fundamental Ciclo II. Para tanto, iremos nos pautar nos preceitos da Educação Linguística, como área de pesquisa e metodologia de ensino e aprendizagem. Além disso, levaremos em consideração as recomendações que os Parâmetros Curriculares Nacionais (PCNs) fazem sobre o trabalho com gêneros textuais e, por fim, enfatizaremos a relevância desse tipo de abordagem, sugerindo, então, uma proposta de sequência didática para o trabalho com o gênero digital blog em sala de aula, conforme descrita por DOLZ, NOVERRAZ e SCHNEUWLY (2004). Para o desenvolvimento dessa proposta, é essencial a escolha de uma metodologia ativa com o propósito de estimular e desenvolver a participação autônoma e crítica do aluno frente à linguagem e à sociedade, como também de orientar os docentes a planejar suas aulas por meio desse recurso prático e eficiente, que atende às expectativas atuais de ensino da língua.
\end{abstract}

PALAVRAS-CHAVE: Educação Linguística. PCNs. Gênero digital. Sequência Didática.

\section{Introdução}

Considerando que, de acordo com os preceitos da Educação Linguística, formar escritores competentes supõe tornar o aprendente um "poliglota dentro de sua própria língua" (BECHARA, 2006, p. 14), a fim de que possa atuar, por meio da linguagem, em diferentes contextos sociais, compreendemos que as atividades de ensino e aprendizagem de leitura e escrita devam se constituir, portanto, em práticas continuadas de produção de textos na sala de aula por meio do contato com diversos gêneros textuais. Esses têm, por sua vez, peculiaridades que precisam ser aprendidas pelos alunos a fim de que adquiram o conhecimento necessário para interagir produtivamente com seus pares em diferentes atividades discursivas.

Nesse contexto, pressupomos que a sequência didática apareça como o meio por excelência para atender a esse objetivo, como também às recomendações dos

`Pontifícia Universidade Católica de São Paulo, São Paulo, Brasil. Imeio: debora.cla@terra.com.br

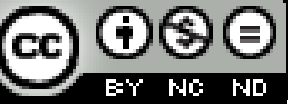

Texto Digital, Florianópolis, v. 10, n. 1, p. 24-45, jan./jul. 2014. ISSNe: 1807-9288 
PCNs, no que diz respeito às propostas de trabalho com gêneros da escrita e da oralidade na escola. Assim, apresentamos, por meio deste trabalho, uma sequência didática que aborda aspectos específicos do gênero em estudo, a saber, blog, o diário na rede.

Para o desenvolvimento desse recurso metodológico, propomos, então, as seguintes etapas: apresentação inicial (levantamento de conhecimentos prévios e produção inicial); módulos (atividades centradas nas particularidades do gênero); produção final (aplicação dos conhecimentos apreendidos). Para tanto, pautamo-nos nas contribuições teóricas desenvolvidas por DOLZ, NOVERRAZ E SCHNEUWLY (2004), levando-se em conta uma metodologia ativa, com o propósito de estimular e desenvolver a participação autônoma e crítica do aluno frente à linguagem e à sociedade.

Bastante pertinente é acrescentar que, na sociedade contemporânea, o desenvolvimento das tecnologias de informação e comunicação suscita o surgimento de novos gêneros. Nessa perspectiva, assumimos que o ensino de língua deve ser alicerçado também nos gêneros digitais emergentes.

Neste ponto, convém ressaltar que, ao analisarmos um material didático voltado para $07^{\circ}$ ano do Ensino Fundamental II, intitulado Tudo é linguagem (BORGATTO; BERTIN; MARCHEZI, 2010), verificamos que ele não apresenta atividades direcionadas ao gênero blog que, a nosso ver, complementariam o conteúdo relacionado ao gênero diário, que se configura, no livro didático, apenas no papel e não na tela do computador.

Por essa razão, optamos por apresentar um conjunto de atividades organizadas, de maneira planejada e sistemática, em torno do gênero digital blog a fim de complementar essa unidade de estudo.

Por fim, na conclusão, tentamos demonstrar que o professor pode, mesmo com o uso do livro didático, planejar propostas de ensino com mais eficiência, como 
também apropriar-se progressivamente da sequência didática, elemento que consideramos indispensável à medida que propõe "uma melhor organização do fazer docente" (PALMA; CANO, 2012, p. 37).

\section{Caracterizando a Educação Linguística}

O ensino da Língua Portuguesa, na perspectiva da Educação Linguística, pautase no desenvolvimento da competência comunicativa que se efetiva pela aquisição de habilidades da oralidade, da leitura e da escrita a fim de que o usuário da língua seja capaz de utilizá-la, de maneira eficaz, nas diferentes situações comunicativas em que estiver inserido.

Nesse sentido, podemos dizer que a competência comunicativa, em sua complexidade, abarca diversas competências tais como: linguística; estratégica; sociolinguística; textual-discursiva; semiológica e literária. Isso prevê conhecimento do código; a capacidade para resolver problemas e tomar decisões, por meio de diferentes recursos, em situações comunicativas concretas; a capacidade de adequação do uso da língua nos mais diferentes contextos; a competência para produzir e compreender diversos tipos de textos; o desenvolvimento de habilidades para a compreensão e análise de formas verbais e não verbais dos meios de comunicação e da publicidade; como também a capacidade de produzir e interpretar textos literários.

O ensino da língua, então, deve propiciar ao aprendente a condição de optar pela variedade que the seja oportuna na situação comunicativa em que se vir envolvido (contexto), bem como de escolher aquela mais adequada às suas intenções e ao estilo que se pretende impor, entendendo e produzindo enunciados, percebendo as diferenças entre uma forma de expressão e outra, "possibilitando-lhe escolher a língua funcional adequada a cada momento" (BECHARA, 2006, p. 14).

Neste ponto, é importante enfatizar que, ao considerarmos o desenvolvimento da competência comunicativa como eixo da Educação Linguística, necessariamente, 
exige-se do professor uma formação ampla e abrangente, isto é, o docente precisa dominar uma gama de conhecimentos que garantam a interdisciplinaridade.

Situados nessa perspectiva, o professor precisa ter a postura de um pesquisador que busca atualizar-se constantemente a fim de poder trazer aos aprendentes, conforme nos aponta BECHARA (2006, p. 24), "conteúdos capazes de levá-los à compreensão do mundo que os cerca, nos mais variados campos do saber", com o propósito de contribuir para a sua formação integral.

Ressaltamos, assim, que seja imprescindível uma contínua formação científica e pedagógica, como também é fundamental que o professor tenha uma postura crítica e reflexiva diante de sua prática pedagógica, a fim de intervir na realidade com a qual convive, colocando em prática, caso seja necessário, uma nova metodologia associada a novos conteúdos de ensino, que partam de situações concretas e que privilegiem a linguagem em suas múltiplas formas, concebendoa, principalmente, como produto de interações sociais.

Gostaríamos, ainda, de acrescentar que, como prevê a Educação Linguística, o ensino de língua voltado para o desenvolvimento da competência comunicativa dos aprendentes pauta-se em concepções de língua e linguagem como interação entre sujeitos, alicerçado em diferentes gêneros textuais, que nos permite entender e se fazer entender em diferentes contextos. Segundo BAGNO (2001, p. 59, grifos do autor), "a escola deve dar espaço ao maior número possível de manifestações lingüísticas, concretizadas no maior número possível de gêneros textuais e de variedades de língua".

Diante de tais considerações, passaremos, então, à analise das considerações que os PCNs (1999) fazem sobre o trabalho com gêneros textuais em sala de aula.

\section{Discutindo os PCNs}

Texto Digital, Florianópolis, v. 10, n. 1, p. 24-45, jan./jul. 2014. ISSNe: 1807-9288 
Os Parâmetros Curriculares Nacionais (PCNs) de Língua Portuguesa estão fundamentados basicamente na teoria dos gêneros textuais, sugerindo que 0 trabalho com a língua materna, no que diz respeito ao ensino de recursos expressivos da linguagem, tanto oral quanto escrita, desenvolva o conhecimento necessário para que os sujeitos envolvidos nos processos de ensino e aprendizagem (docente/discente) saibam adaptar suas atividades linguísticas, com êxito, aos eventos comunicativos.

Convém registrar que os gêneros textuais surgem de acordo com sua função na sociedade. Seus conteúdos, seu estilo e sua forma estão sujeitos a essa função. São definidos, portanto, por seus propósitos comunicativos. Isso quer dizer que conhecer um gênero não significa apenas conhecer suas características formais, mas, antes de tudo, entender sua função e saber, desse modo, interagir adequadamente.

É importante comentar que para o professor pode ser relativamente simples explicar a estrutura composicional de uma carta, por exemplo. Contudo, acreditamos que discutir a função social desse gênero seja muito mais desafiador. É importante pensar em para quem se escreve; por que se escreve; quando e onde escreve; no que o leitor conhece efetivamente sobre o tema; como fazer-se compreender; que variante linguística é mais adequada, etc. Consideramos que tais questões possibilitam ao aprendente o conhecimento necessário para interagir produtivamente com seus pares em diferentes atividades discursivas.

Nesta perspectiva, a justificativa para o desenvolvimento do trabalho com a língua materna sob a ótica dos gêneros textuais que perpassa o documento é a de que:

Toda educação verdadeiramente comprometida como exercício da cidadania precisa criar condições para o desenvolvimento da capacidade de uso eficaz da linguagem que satisfaça suas necessidades pessoais que podem estar relacionadas às ações efetivas do cotidiano, à transmissão e busca de informação, ao exercício da reflexão (PCN-EF, 1999, p. 30). 
Para atender ao objetivo acima exposto, os PCNs salientam que a noção de gênero precisa ser tomada como objeto de ensino-aprendizagem. Nesse sentido, BAGNO (2002, p. 54, grifos do autor) enfatiza que:

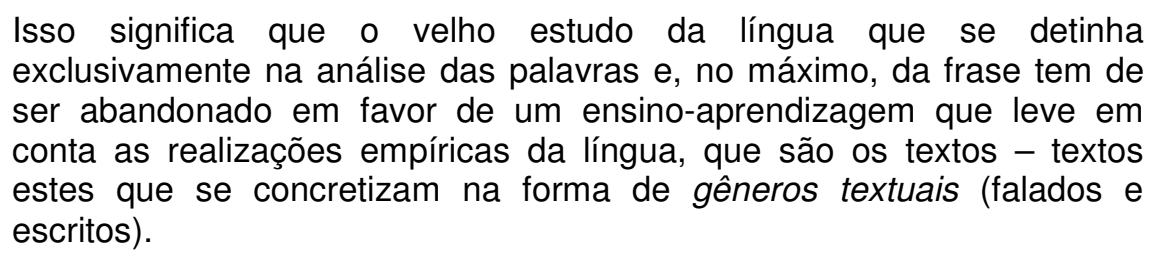

É desse aspecto que trataremos a seguir.

\section{Trabalhando com gêneros textuais em sala de aula}

De acordo com BAKHTIN (1979, p. 280), gêneros textuais são "tipos relativamente estáveis de enunciados", construídos historicamente e disponíveis na cultura.

Entendemos que as atividades humanas, em sua maioria, estão relacionadas ao uso da língua que se materializa por meio dos textos. Naturalmente, cada situação comunicativa requer, por parte dos falantes, certo domínio dos gêneros para que venham a atingir os seus propósitos enunciativos. Por essa razão, MARCUSCHI (2005a, p. 35) considera o trabalho com gêneros textuais "uma oportunidade de se lidar com a linguagem em seus mais diversos usos autênticos no dia a dia".

Como se percebe, o trabalho com gêneros propicia aos aprendentes um envolvimento concreto em situações reais de uso da linguagem de maneira que possam escolher meios adequados aos propósitos comunicativos que almejam alcançar em contextos de comunicação diversos.

É importante ressaltar que existe um número quase ilimitado de gêneros, que variam em função da época, da cultura, das finalidades sociais, de modo que a escola precisa priorizar aqueles que mereçam uma abordagem mais aprofundada. 
Atualmente, o desenvolvimento das tecnologias de informação e comunicação suscita, segundo BAGNO (2002), o aparecimento de novos gêneros, que implicam novos comportamentos sociais referentes às práticas de utilização da linguagem oral e escrita.

MARCUSCHI (2005b) pontua que entre os gêneros digitais emergentes mais praticados e que vêm sendo estudados até agora estão os e-mails, fóruns de discussão, chats e blogs (diários na rede).

Levando-se em conta, então, o momento sócio-econômico-cultural em que o aprendente vive e o contato que possui com essa diversidade textual, faz-se necessário, de alguma forma, que a escola ofereça propostas de atividades que contemplem também o trabalho com esses novos gêneros.

\begin{abstract}
Além disso, colocar os alunos em situação de comunicação o mais próximo possível da sua realidade cotidiana, de forma que as práticas textuais façam sentido para eles, é essencial para que possam dominálas, pois o gênero, ao ser veiculado em outro lugar fora daquele em que circula habitualmente, acaba por sofrer transformações, passando de gênero de comunicação a gênero de aprendizagem. Assim, ao trabalhar com os gêneros na escola, deve-se ter o cuidado de fazer com que o aluno perceba que pode utilizá-los no seu meio social e que ele faz parte, ou pode fazer parte, das suas atividades sociais. (FORTUNATO, 2012, p. 7-8)
\end{abstract}

Assim, consideramos que quanto maior for a vivência dessas práticas comunicativas na sala de aula, maior será a capacidade dos alunos de refletir sobre suas realizações em contextos reais de comunicação para que se tornem aptos a atuar de forma crítica e produtiva além do âmbito escolar.

Situados nessa perspectiva, entendemos que a Sequência Didática aparece como meio para atender às recomendações dos $\mathrm{PCNs}$ no que diz respeito às propostas de trabalho com gêneros da escrita e da oralidade. 


\section{Entendendo "sequência didática" com base em metodologia ativa}

Segundo DOLZ, NOVERRAZ E SCHNEUWLY (2004, p. 82), "uma 'sequência didática' é um conjunto de atividades escolares organizadas, de maneira sistemática, em torno de um gênero textual oral ou escrito".

Sua estrutura de base pode ser representada pelo esquema (Figura 1) abaixo:

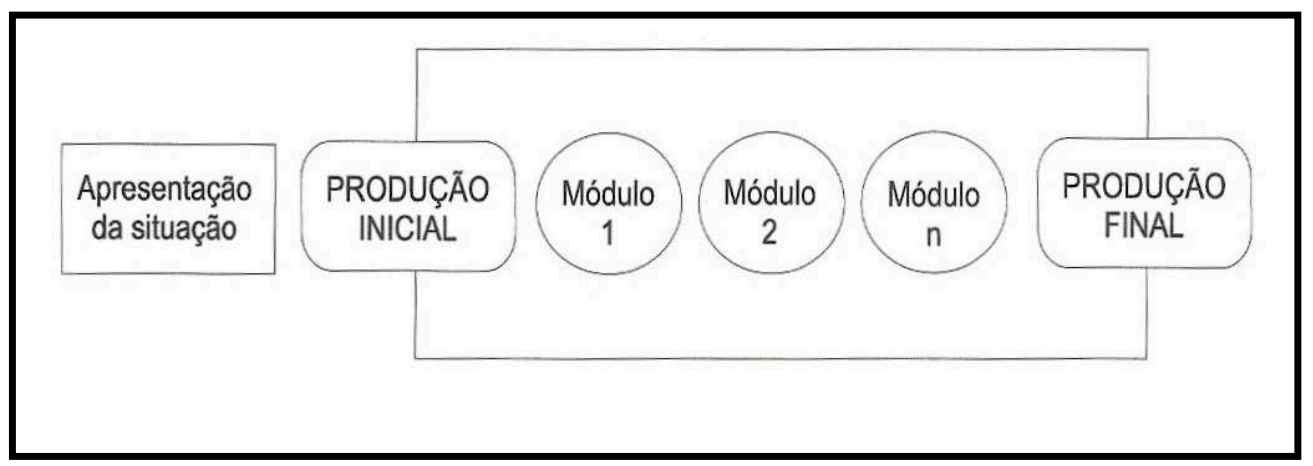

Fig. 1: exemplo de sequência didática (SCHENEUWLY; NOVERRAZ; DOLZ, 2004, p. 83)

Embora não esteja registrado na figura acima, esses autores (2004) destacam a importância de se realizar a sequência didática no âmbito de um projeto de classe, pois este torna as atividades de aprendizagem significativas e pertinentes.

Segundo os PCNs (1999), os projetos proporcionam aos aprendentes situações em que a linguagem oral, escrita, leitura e produção de textos se inter-relacionam de maneira contextualizada e, por isso, são atividades socialmente significativas, pois se inscrevem em contextos de comunicação autênticos com suas exigências e especificidades.

Assim, a negociação do projeto com os alunos constitui a primeira etapa da sequência didática, isto é, na apresentação da situação, o professor expõe aos alunos as atividades de linguagem a serem executadas. "Permite, portanto, fornecer ao aluno todas as informações necessárias para que conheçam o projeto comunicativo visado e a aprendizagem da linguagem a que está relacionado" (DOLZ; NOVERRAZ; SCHNEUWLY, 2004, p. 85). 
$\mathrm{Na}$ produção inicial, os alunos apresentam uma primeira produção e, assim, tomam consciência das representações que têm da atividade inicialmente proposta. Trata-se, na verdade, de um material que possibilita ao professor compreender o que não ficou claro na apresentação inicial, bem como reconhecer as dificuldades de expressão oral e/ou escrita na produção do aluno. Essa etapa propicia um levantamento diagnóstico dos problemas mais relevantes.

A fase dos módulos consiste em se trabalhar as dificuldades e problemas que apareceram na primeira produção e em se oferecer aos aprendentes os instrumentos necessários para superá-los. Para isso, DOLZ, NOVERRAZ E SCHNEUWLY (2004) recomendam diversificar as atividades, levando-se em conta três categorias: observação e análise de textos orais e escritos; produção simplificada de textos, em que são focalizados mais especificamente aspectos da textualização; e as de elaboração de uma linguagem comum, cujo objetivo está associado à elaboração de critérios operacionais de avaliação dos textos para todos os envolvidos.

Finaliza-se a sequência didática com uma produção final, em que o aluno põe em prática os conhecimentos adquiridos, medindo, juntamente com o professor, os progressos alcançados. O docente, se assim desejar, pode realizar uma avaliação somativa, em que verifica a conformidade dos resultados finais com os objetivos de aprendizagem previamente estabelecidos no intuito de validar ou certificar a aprendizagem.

Convém registrar que esse procedimento é aplicável tanto ao trabalho com gêneros escritos quanto com gêneros orais, e a importância de se trabalhar com sequências didáticas está relacionada, principalmente, à possibilidade de criar, de maneira coerente e adequada, contextos de produção precisos, de desenvolver atividades múltiplas e variadas, que permitirão aos aprendentes a apropriação das noções, técnicas e dos instrumentos necessários ao desenvolvimento de suas capacidades de expressão oral e escrita, nas mais variadas situações sociais, que permeiam a nossa vida em sociedade. 
Como se percebe, a sequência didática é um procedimento de fundamental importância no ensino e aprendizagem da Língua Portuguesa, uma vez que permite uma interação entre os sujeitos desse processo (professor e alunos) e o texto (gênero textual).

Nessa perspectiva, convém destacar que o procedimento de sequência didática com base em metodologia ativa prevê a superação de desafios, a resolução de problemas e a construção do conhecimento novo a partir dos conhecimentos prévios dos aprendentes. Respeita-se, sobretudo, o ritmo e o estilo de aprendizagem de cada aluno.

Nesse sentido, o professor assume, portanto, o papel de um facilitador ou orientador do processo de ensino-aprendizagem, em que "educador e educando aprendem juntos, numa relação dinâmica na qual a prática, orientada pela teoria, reorienta essa teoria, num processo de constante aperfeiçoamento" (GADOTTI, 2001, p. 253).

Assim, na metodologia ativa de aprendizagem, o processo de ensinoaprendizagem passa a ser centrado no estudante, que deixa de ser um mero receptor passivo de informações para ser agente e principal responsável pela construção de seu conhecimento.

São muitas as possibilidades de metodologia ativa que podem contribuir para o desenvolvimento da autonomia do aluno, mas, em síntese, como descrita anteriormente, "esta metodologia possibilita colocar em prática uma pedagogia problematizadora, pelo que é associada inegavelmente aos ensinamentos de Paulo Freire" (APUD BERBEL, 2011, p. 34).

Vejamos, então, a seguir a apresentação de uma sequência didática com base em metodologia ativa aplicando os conceitos desenvolvidos até agora (itens 1 a 4). 


\section{Proposta de Sequência Didática, envolvendo o trabalho com o gênero digital blog}

A coleção analisada para este trabalho foi Tudo é linguagem (BORGATTO; BERTIN; MARCHEZI, 2010). O exemplar que escolhemos foi desenvolvido para o $7^{\circ}$ ano do Ensino Fundamental II. Selecionamos a terceira unidade denominada "Relato e memória" e pudemos observar que as autoras têm como referência principal a tipologia relatar em situações de aprendizagem centradas no gênero diário.

Um ponto que nos chamou bastante a atenção foi o fato do livro não apresentar nenhuma referência ao gênero blog que, a nosso ver, complementaria as atividades que estão relacionadas ao gênero diário, pois tomamos como pressuposto a concepção de MARCUSCHI (2005b, p. 29, grifos do autor) que pontua:

weblog (blogs; diários virtuais) - são os diários pessoais na rede; uma escrita autobiográfica com observações diárias ou não, agendas, anotações, em geral muito praticados pelos adolescentes na forma de diários participativos.

Uma vez que os aprendentes interagem constantemente por meio da escrita no universo da rede, consideramos que a abordagem desse gênero seja relevante, visto que os diários on-line têm papel de destaque no cotidiano dos adolescentes, como também nos aponta ELIAS (2011, p. 160):

\footnotetext{
Essa prática comunicativa ganhou inúmeros adeptos entre diferentes faixas etárias e vem assumindo novas variedades e novas funções que a diferencia do diário no papel, haja vista a existência de blogs profissionais, institucionais, corporativos e jornalísticos, além dos pessoais.
}

Entendemos que, em tempos de cultura digital, cabe à escola, portanto, abrir espaço a essa diversidade, como também reconhecer o potencial pedagógico desse gênero. Outro desafio que se apresenta, apontado nos estudos de DOLZ, 
NOVERRAZ E SCHNEUWLY (2004), diz respeito ao desenvolvimento de propostas de atividades didáticas que busquem conduzir o aluno à comunicação autêntica ou a uma situação comunicativa próxima aos usos reais do gênero.

Desse modo, "uma sequência didática tem, precisamente, a finalidade de ajudar o aluno a dominar melhor um gênero de texto, permitindo-Ihe, assim, escrever ou falar de uma maneira mais adequada numa dada situação de comunicação" (DOLZ, NOVERRAZ, SCHNEUWLY, 2004, p. 83, grifo dos autores).

Situados nessa perspectiva, consideramos, ainda, que seja importante complementar essa unidade de estudo, proporcionando aos alunos oportunidades de contato com o gênero digital blog a fim de que se tornem cidadãos letrados, capazes de utilizar as práticas de leitura e escrita exigidas também no contexto da tecnologia e, sobretudo, que possam ser efetivamente utilizadas por eles na sua vida fora dos muros da escola.

Torna-se relevante ainda comentar que o gênero, conforme mencionado, possui diversas variedades e funções, tanto no contexto da escola quanto no da vida social; e, por isso, deve ser trabalhado várias vezes durante a escolaridade.

Assim, decidimos trabalhar com a variedade que nos parece mais importante e apropriada à idade dos aprendentes, isto é, a do diário on-line, que deixa de ser, quando publicado na rede, uma escrita íntima e privada, solicitando, assim, novas estratégias referentes ao uso da língua e recursos próprios à sua prática nesse meio.

Nosso intuito, então, é desenvolver nos alunos uma relação consciente com o seu comportamento de linguagem em situações de comunicação diversificadas, tais como: as práticas de escrita de foro íntimo (diário íntimo no papel) e de foro público (diário pessoal online), levando-se em conta os principais elementos linguístico-discursivos trabalhados no livro didático, tais como: elementos composicionais (como a sequência dos fatos é apresentada); tipo de linguagem 
empregada; marcas de tempo e espaço; formas verbais (pessoas do discurso/ tempo verbal); pontuação e efeitos de sentido; recursos gráfico-visuais e estratégias de contextualização (quem escreve; para quem se escreve; onde e quando; com que intenção).

Diante do exposto, apresentaremos, a seguir, a nossa proposta de sequência didática, que complementa a Unidade 3 - "Relato e memória" - do livro didático Tudo é Linguagem ( $7^{\circ}$ ano) e propõe a refacção do texto escrito no livro didático para o gênero blog.

Cabe acrescentar que utilizaremos a expressão refacção, conforme o faz MARCUSCHI, (2010, p. 23), no que se refere à mudança de uma escrita para a outra, reescrevendo o mesmo texto, "sem envolver as variáveis que incidem no caso da retextualização [...], com a passagem da fala para a escrita".

\subsection{Explorando o gênero blog na escola}

a. Atividades: produção de um diário pessoal on-line (blog) e de um blog pedagógico (de autoria coletiva - professor com alunos). Refacção do texto (página de diário pessoal) escrito no livro didático para publicação no blog. Socialização do conhecimento, no blog pedagógico, por meio de relato pessoal.

\section{b. Objetivos:}

1. Desenvolver o conhecimento do gênero blog no que diz respeito à leitura (observação e análise de textos), produção e reflexão linguística;

2. Trabalhar as mudanças de um texto no seu interior (uma escrita para outra, reescrevendo o mesmo texto) por meio do processo de refacção;

3. Introduzir o aluno na prática social na qual o gênero circula.

\section{c. Desenvolvimento:}


Apresentação da situação: esta etapa deve ser realizada em sala de aula e pressupõe a ativação dos conhecimentos prévios que os alunos têm acerca do que é blog (o que eles conhecem; se possuem ou leem com frequência, variedade, funções, semelhanças e diferenças entre o diário íntimo e o diário online, etc.). É interessante que o professor anote as palavras-chave na lousa a fim de que essas considerações possam ser acionadas quando necessário, tanto para ele quanto para os alunos. Em seguida, o docente pode propor a leitura de duas figuras (por meio de slides) que representem o respectivo gênero e, então, solicita que os aprendentes observem e apontem as suas particularidades. Esse primeiro momento é o de reconhecimento. Convém observar como os alunos apreendem as características do gênero e quais detalhes consideram mais relevantes. A partir desse procedimento, apresenta-se a proposta de sequência didática.

Módulo I: nesse módulo, depois de apresentada a proposta de trabalho, os alunos devem ser conduzidos ao laboratório de informática. Propomos, nessa etapa, que o professor indique endereços de blogs pessoais a fim de que os alunos analisem como o blog é estruturado em um contexto comunicativo real, bem como aprendam a buscar as fontes em que o gênero se propaga. Em seguida, em duplas, deve pedir para que façam anotações em uma ficha de atividades quanto aos seguintes aspectos: tipo de linguagem empregada; marcas de tempo e espaço; formas verbais; recursos semióticos; pontuação; estratégias de contextualização - elementos trabalhados no livro didático. Isso irá ajudá-los a apreender as principais características do gênero. Nesse momento, pode-se explicar como a postagem de comentários se configura, levando-os também a interagir virtualmente nas redes sociais, solicitando, assim, que publiquem, nos blogs consultados, sugestões e comentários e/ou, até mesmo, participem das enquetes.

Avaliação: as anotações na ficha de atividade podem ser um instrumento de avaliação dos alunos. 
Módulo II: esse módulo tem por objetivo um estudo comparativo dos elementos linguístico-discursivos presentes no diário. Esse é um momento em que muito se pode aprender. Dessa forma, inicia-se a reflexão e discussão das informações coletadas no módulo anterior por meio de perguntas norteadoras, tais como:

1. As indicações de tempo e espaço estão claras? Dão veracidade ao relato?

2. Em que pessoa o relato é feito? Que tempo verbal é empregado? Por quê?

3. Como os sinais de pontuação foram empregados? Que efeitos de sentido produzem?

4. Você observou a linguagem dos textos? Qual é a variedade empregada? Ela é formal ou mais espontânea?

5. Qual é o perfil dos interlocutores (quem escreve e para quem se escreve)?

6. Qual é o suporte/veículo em que os diários são publicados?

7. Qual é a estrutura composicional? Como se apresenta a sequência dos fatos narrados?

8. Que recursos (imagem, som, vídeo, foto, gravuras, links, etc.) foram utilizados nos diários? Que efeitos esses tipos de registro produzem na escrita?

9. O que os adolescentes costumam registrar nos diários? Com que intenção?

10. Qual é, então, a finalidade do gênero?

Essa atividade pode ser realizada em grupo. A seguir, os alunos apresentam oralmente as ideias discutidas. Na próxima etapa, elaboram conjunta e colaborativamente (professor e alunos) um quadro-comparativo que apresente as características globais do diário (estrutura composicional, propriedades linguístico-discursivas e finalidades) a fim de organizar e sistematizar os principais elementos que compõem o gênero estudado (diário no papel e na tela do computador). Convém destacar que, nos Módulos I e II, levamos em conta o conceito de "zona de desenvolvimento proximal", elaborado por VYGOTSKY (1999), privilegiando a integração dos alunos por meio do trabalho em duplas e 
grupos, isto é, momentos em que o professor mescla aqueles que têm maior facilidade de aprender com os que precisam de assistência, de modo que esses sejam capazes de aplicar um nível de conhecimento mais elevado do que seria possível sem ajuda.

Avaliação: o professor pode avaliar a apresentação oral das ideias discutidas pelos grupos.

Módulo III: essa etapa prevê a produção do blog. Neste ponto, bastante pertinente é acrescentar que esse gênero propicia uma praticidade de construção e simplicidade de manutenção sem exigir do usuário um conhecimento técnico especializado. No laboratório, portanto, o professor pode sugerir endereços de sites e provedores da internet que explicam, passo a passo, como montar um blog. Os alunos os acessam e procedem, então, à montagem do mesmo.

Avaliação: pode-se avaliar o desempenho dos alunos na criação do blog.

Módulo IV: chega a hora de reconhecer no texto os elementos estudados e preparar-se para utilizá-los na refacção do texto (no papel) para o blog, adequando a produção ao gênero de acordo com o contexto comunicacional. Assim, o professor conduz os alunos a retomar os principais elementos linguístico-discursivos estudados por meio do quadro-comparativo. Em seguida, propõe a reescrita do texto de acordo com as peculiaridades do gênero e publicação do texto final no meio eletrônico. Pede aos estudantes que disponibilizem o endereço do blog ao docente e colegas para que todos possam comentar sobre a publicação. É interessante que os alunos revisem e reescrevam trechos, levando-se em conta os comentários postados. O professor pode, inclusive, sugerir uma autoavaliação da produção escrita, levando-se em conta os seguintes aspectos: adequação do texto ao gênero; atendimento à intenção; adequação da linguagem; emprego de recursos tecnológicos; processo de revisão e reescrita. 
Avaliação: neste momento, para avaliar o desempenho dos alunos, seria interessante selecionar dois ou três blogs a fim de avaliar conjuntamente os resultados com a turma.

Pressupomos que, nessa etapa, os alunos já se encontrem familiarizados com o gênero e, por isso, sejam capazes de perceber o que as ferramentas tecnológicas Ihes proporcionam no que diz respeito ao processo de refacção do texto escrito no livro didático para a publicação na rede (blog).

Neste ponto, é preciso comentar que as autoras do livro didático sugerem no caderno de produção de textos - "Tramas e textos" - uma produção com abordagem interdisciplinar a partir da exibição de um vídeo ( $A$ invenção do fósforo); da análise de uma imagem (Mãos com esfera refletora, de Escher); da leitura do Diário de Clarice Bean; e, finalmente, do áudio de um poema (e começo aqui, de Haroldo de Campos). A atividade propõe que os alunos relatem as suas impressões ao verem sua imagem refletida em um espelho, em uma vitrine, etc. Solicita também que os aprendentes atentem nas escolhas de linguagem; na apresentação da sequência dos fatos; em marcas de tempo e espaço, em suas intenções, bem como selecionem os recursos visuais que serão utilizados (colagem, desenho).

Esperamos que, com a ampliação de seu conhecimento sobre o blog, reestruturem essa primeira produção (do livro didático), tomando por base as características do gênero em estudo (o que muda no texto quando transposto para o meio eletrônico) e reconheçam também o que os recursos tecnológicos Ihes proporcionam em sua página do diário virtual, tal como: a inserção do vídeo; da imagem e/ou, até mesmo, do áudio.

d. Produção final: nesta última etapa, iremos propor a criação de um blog pedagógico, em que cada aluno deve publicar um relato acerca das aprendizagens efetuadas ao longo da sequência, como também avaliar os progressos realizados; fazer comentários (posts), levando-se em conta as 
considerações apresentadas pelos colegas e professora; e, finalmente, indicar novos projetos que explorem o gênero como a produção de relatos de viagem e/ou diários de pesquisa.

\title{
6 Buscando as palavras finais...
}

Por meio deste trabalho, consideramos que a proposta de sequência didática desenvolvida para o gênero digital blog encontra respaldo, principalmente, nas palavras de RODRIGUES (2008, p. 56):

\begin{abstract}
Considerar o blog um recurso pedagógico é entendê-lo como um espaço de acesso a informação especializada e um espaço de disponibilização de informação. Como estratégia pedagógica, os blogs podem ser utilizados como: 1. um portfólio digital; 2. um espaço de intercâmbio e colaboração; 3. um espaço de debates; 4. um espaço de integração, entre outros.
\end{abstract}

Bastante pertinente é acrescentar também que, em nossas análises, verificamos que grande parte dos livros didáticos apenas situa os aprendentes em relação ao gênero em estudo e sugere um endereço eletrônico que os auxilie na montagem de um blog. Características e funcionalidades desse gênero não fazem parte do conteúdo dos exemplares.

Em nossas pesquisas, pudemos observar que há metodologias que utilizam o blog como suporte/ferramenta para o trabalho com outros gêneros textuais. Em razão disso, neste trabalho, propusemos uma sequência didática que realmente leva os adolescentes, segundo DOLZ, NOVERRAZ, SCHNEUWLY (2004), a dominar o gênero, compreendendo as suas peculiaridades, como também a sua função, a fim de que possam utilizá-lo de maneira adequada em um contexto real de comunicação.

É importante dizer que atentamos para o fato de que nossa proposta não excedesse 15 aulas. Conforme nos apontam esses autores (2004, p.193), isso deve ser levado em conta mesmo que a ideia de globalidade subsista, visto que 
os objetivos didáticos devem ser repartidos "em função do que parece mais importante e mais apropriado a uma determinada idade e a uma determinada variedade $[\ldots]$...

De modo geral, percebemos que a elaboração da sequência didática confere autonomia ao professor, pois ele pode refletir sobre a sua prática pedagógica, desenvolvendo atividades que estimulem a participação efetiva dos aprendentes. Além disso, busca atingir as reais necessidades dos alunos, ao mesmo tempo em que exerce o seu papel: formar cidadãos que atuem de forma crítica, participativa e autônoma na sociedade.

Torna-se relevante comentar que, ao trabalharmos com o gênero blog, procuramos estimular as habilidades de leitura, escrita, oralidade e letramento digital, de maneira intercomplementar, por acreditar que, muito antes de serem práticas linguísticas e cognitivas, são práticas sociais.

Outro ponto a ser destacado é que, nas atividades propostas pela sequência, tivemos a preocupação de contextualizar o trabalho de produção textual, isto é, optamos por incluir a circulação do texto em um contexto sócio-interacional efetivo, pois é bastante comum, em livros didáticos, que as redações assumam um caráter circular, denominadas por MARCUSCHI e CAVALCANTE (2005, p. 242) como "endógenas", isto é, aquelas que se originam e se esgotam nelas mesmas (produção feita na escola, pela escola e para a escola), dando lugar à função meramente pedagógica. Assim, em nosso projeto, buscamos articular 0 gênero escolar diário com práticas sociais de leitura e escrita (produção de blogs) a fim de que circulem em contextos reais de comunicação.

Dessa forma, pressupomos que contribuímos para a formação de um usuário competente e, conforme nos aponta BECHARA (2006, p. 14), capaz de tornar-se um "poliglota dentro de sua própria língua".

Essa concepção encontra reforço nas ideias de BATHIA (2009, p. 185-187): 
A intenção comunicativa só será alcançada se todos os participantes compartilham não só o mesmo código linguístico, mas também o conhecimento do gênero, o que inclui conhecer sua construção, interpretação e uso. [...] há vários discursos que só são acessíveis para aqueles que detêm o conhecimento dos gêneros utilizados, bem como 0 seu funcionamento, não para aqueles que estão de fora.

Nesse sentido, consideramos que, por meio de nossa sequência didática, esses aspectos foram levados em conta, visto que as atividades propostas procuraram contemplar a construção, interpretação e uso do gênero escolhido a fim de que os alunos possam utilizá-lo de modo consciente e crítico.

Por fim, convém registrar que este processo de complementar/repensar a aplicabilidade dos materiais didáticos com a sequência didática constitui-se em uma proposta bastante significativa, pois tem por objetivo auxiliar o planejamento e organização do fazer docente com mais eficiência, como também conduzir os docentes a elaborar, por meio da formação inicial ou contínua, outras sequências, apropriando-se progressivamente desse procedimento, elemento que consideramos indispensável à medida que propõe um modo preciso de trabalhar em sala de aula.

\section{DIARY IN THE NETWORK: PROPOSAL OF DIDACTIC SEQUENCE FOR DIGITAL GENRE BLOG}

ABSTRACT: The objective of this work is to propose a didactic sequence that complements the content of educational material aimed at elementary school students. To do so, we will abide in the precepts of Linguistic Education as an area of research and methodology of teaching and learning. In addition, we will consider the recommendations that the National Curricular Parameters (NCPs) are about working with text genres and, finally, we will emphasize the relevance of this approach, then, suggesting a proposal of didactic sequence to work with digital genre blog in the classroom, as described by DOLZ, NOVERRAZ and SCHNEUWLY (2004). For the development of this proposal, it is essential to choose an active methodology, in order to stimulate and develop critical and autonomous participation of the student ahead to language and society, but also to guide teachers to plan their lessons through this resource practical and efficient, which meets current expectations of language teaching.

KEYWORDS: Linguistic Education. NCPs. Digital Genre. Didactic Sequence. 


\section{Referências}

BAGNO, M. Português ou brasileiro? Um convite à pesquisa. São Paulo: Parábola, 2001.

A Inevitável travessia: da prescrição gramatical à educação linguística. In: LÍNGUA MATERNA - letramento, variação \& ensino. São Paulo: Parábola, 2002.

BAKHTIN, M. Os gêneros do discurso. In: Estética da criação verbal. São Paulo: Martins Fontes, 1979.

BECHARA, E. Ensino da Gramática. Opressão? Liberdade? 12. ed. São Paulo: Ática, 2006.

BERBEL, N. A. N. As metodologias ativas e a promoção da autonomia de estudantes. Semina: Ciências Sociais e Humanas, Londrina, v. 32, n. 1, p. 25-40, jan./jun.2011.Disponível

em: <http://www.proiac.uff.br/sites/default/files/documentos/berbel_2011.pdf>. Acesso em: 15 nov. 2013.

BHATIA, V. K. Análise de gêneros hoje. In: BEZERRA, B; BIASE, B; CAVALCANTE, M. M. (Orgs.). Gêneros e sequências textuais. Recife: Edupe, 2009. p. 159-196.

BRASIL, Ministério da Educação. Parâmetros curriculares nacionais - Ensino Fundamental - Língua Portuguesa. Brasília: SEF/MEC, 1999.

BORGATTO, A. T.; BERTIN, T. MARCHEZI, V. Tudo é linguagem, $7^{\circ}$ ano. 2 . ed. São Paulo: Ática, 2010.

Tramas e textos: caderno de produção de textos, $7^{\circ}$ ano. 2. ed. São Paulo: Ática, 2010.

DOLZ, J; NOVERRAZ, M; SCHNEUWLY, B. Sequências didáticas para o oral e a escrita: apresentação de um procedimento. In: Gêneros Orais e Escritos na Escola (Bernard Schneuwly e Joaquim Dolz e colaboradores). Campinas: Mercado de Letras, 2004, p. 95-128.

ELIAS, V. M. S. (Org.). Ensino de Língua Portuguesa: oralidade, escrita e leitura. São Paulo: Contexto, 2011.

FORTUNATO, G. C. A sala de aula, o blog e os adolescentes: a construção textual no espaço do papel e da tela. Anais do SIELP. v. 2, n. 1. Uberlândia: EDUFU, $2012 . \quad$ Disponível em: 
$<$ http://www.ileel.ufu.br/anaisdosielp/pt/arquivos/sielp2012/454.pdf>. Acesso em: 16 nov. 2013.

GADOTTI, M. História das idéias pedagógicas. 8. ed. São Paulo: Ática, 2001.

MARCUSCHI, B.; CAVALCANTE, M. Atividades de escrita em livros didáticos de língua portuguesa: perspectivas convergentes e divergentes. In. COSTA VAL, M. G.; MARCUSCHI, B. (Orgs.). Livros didáticos de língua portuguesa: letramento, inclusão e cidadania. Belo Horizonte: Autêntica, 2005.

MARCUSCHI, L. A. Gêneros Textuais: definição e funcionalidade. In: DIONISIO, A.; MACHADO, A.; BEZERRA, M. (Orgs.). Gêneros Textuais e Ensino. 2. ed. Rio de Janeiro: Lucerna, 2005a. p. 19-36,

- Gêneros textuais emergentes no contexto da tecnologia digital. In: MARCUSCHI, L.; XAVIER, A. C. (Orgs.). Hipertexto e gêneros digitais: novas formas de construção do sentido. 2. ed. Rio de Janeiro: Lucerna, 2005b.

Paulo: Cortez, 2010.

Da fala para a escrita: atividade de retextualização. 10. ed. São

PALMA, D. V.; CANO, M. R. O. Língua Portuguesa. Coleção: A reflexão e a prática no ensino. v. 1. São Paulo: Ed. Blucher, 2012.

RODRIGUES, C. O uso de blogs como estratégia motivadora para o ensino de escrita na escola. Dissertação (Mestrado).UNICAMP, SP, [s.n.], 2008. Disponível em: <http://pt.scribd.com/doc/13499300/dissertacaousodosblogs>. Acesso em: 15 nov. 2013.

VYGOTSKY, L. A formação social da mente: o desenvolvimento dos processos psicológicos superiores. São Paulo: Martins Fontes, 1999.

Texto recebido em: 07/03/2014. Texto aceito em: 14/07/2014. 